\title{
Profile of Obstetric Morbidity Among Maternal Intensive Care Unit Patients
}

\author{
Shakya B, Chaudhary P, Tumbahangphe M \\ Department of Obstetrics and Gynaecology, Paropakar Maternity and Women's Hospital, Kathmandu, Nepal
}

Received: Janurary 5, 2014; Accepted: July 12, 2014

\begin{abstract}
Aims: The objective of the study was to determine the outcome of the obstetric admissions to Maternal Intensive Care Unit in the setting of a tertiary care hospital.

Methods: This was a cross-sectional study undertaken at Paropakar Maternity and Women's Hospital from April 1, 2012 to March 31, 2013. Patient characteristics, gestational age, booking status, indication for intensive care unit admission, intervention, length of stay and outcome were analyzed.

Results: During the study period, 19,247 deliveries occurred and 247 women were admitted to maternal intensive care unit. This accounts for $1.28 \%$ of all deliveries. The most common indication of admission to intensive care unit was hypertensive disorders in pregnancy (45.3\%) followed by obstetric hemorrhage (39.27\%). Sepsis was the cause in ten (4.04\%) cases. Ten cases $(4.04 \%)$ of postpartum hemorrhage were managed by balloon tamponade, seven $(2.83 \%)$ by B-Lynch compression sutures and three (1.21\%) necessitated cesarean hysterectomy. Among 18 cases of ruptured uterus, 13 (5.26\%) were repaired while five $(2.02 \%)$ required hysterectomy. Maternal mortality occurred in four $(1.61 \%)$ of the cases. One was a case of severe preeclampsia who died on 4th post-operative day due to pulmonary embolism, another due to anesthetic complication and the other two died of septic shock and multiorgan failure.
\end{abstract}

Conclusions: Hypertensive disorders of pregnancy and obstetric hemorrhage appeared as the major risk factors influencing maternal outcomes in obstetric patients.

Keywords: intensive care unit; maternal morbidity; maternal mortality.

\section{INTRODUCTION}

Although pregnancy and delivery are physiological processes, any sort of morbidity that might be encountered during these time courses might lead to fatal consequences regarding not only the fetus but the mother as well. Each year nearly 529,000 women die globally due to pregnancy related causes. ${ }^{1}$ Maternal death is a tragic event, as pregnant women are generally young and healthy patients. ${ }^{2}$ Despite developments in diagnosis and treatment, maternal death is still a serious public health problem. ${ }^{3,4}$ The transfer of an obstetrical patient to the intensive care unit (ICU) is considered to be an indicator of maternal morbidity. ${ }^{5}$ The complications that develop during pregnancy or in the postpartum period may be lifethreatening and may require ICU transfer. ${ }^{4}$ It is now believed that between 0.1 to $0.9 \%$ of pregnant women

\section{CORRESPONDENCE}

Dr Beemba Shakya

Department of Obstetrics and Gynaecology, Paropakar Maternity and Women's Hospital, Kathmandu, Nepal.

Email: docbeemba@yahoo.com

Phone: +977-9841729847 have complications requiring ICU admission. ${ }^{6}$ Early admission and appropriate management of critical obstetrical patients to the ICU decreases maternal morbidity and mortality. There is growing evidence that admission of high risk obstetric patients to the ICU is associated with a fall in maternal mortality. ${ }^{7}$ The objective of the present study was to determine the outcome of the obstetric admissions to Maternal Intensive Care Unit (MICU) in the setting of a tertiary care hospital.

\section{METHODS}

This was a cross-sectional study undertaken at Paropakar Maternity and Women's Hospital (PMWH) from April 1, 2012 to March 31, 2013. Ethical approval was obtained from the hospital and informed consent was obtained from the patients. Patient characteristics, gestational age, booking status, indication for ICU admission, intervention in ICU, length of ICU stay and outcomes were analyzed. 


\section{RESULTS}

During the study period, a total of 19,247 deliveries occurred and 247 women were admitted to MICU. This accounts for $1.28 \%$ of all deliveries. Majority of the ICU admissions occurred in 20-34 years of age (79.7\%), $19(7.69 \%)$ in 35-39 years and eight $(3.23 \%)$ occurred 40-49 years age group. Most of them were nullipara 117 (47.3\%), multipara 124 (50.2\%) and grandmultipara $6(2.42 \%)$. Postpartum cases were more $(52.3 \%)$ than antepartum cases $(47.3 \%)$ and unbooked cases were $(70.8 \%)$ (Table 1$)$.

\begin{tabular}{|lc|}
\hline $\begin{array}{l}\text { Table 1. Obstetric characteristics of the patients } \\
(\mathrm{n}=247) .\end{array}$ & Number $(\%)$ \\
\hline Age & $23(9.31)$ \\
$\mathbf{1 5 - 1 9}$ & $197(79.75)$ \\
$35-34$ & $19(7.69)$ \\
$40-49$ & $8(3.23)$ \\
Parity & \\
0 & $117(47.36)$ \\
$1-2$ & $102(41.29)$ \\
$3-4$ & $22(8.90)$ \\
$\geq 5$ & $6(2.42)$ \\
Gestational age (weeks) & \\
$<13$ & $15(6.07)$ \\
$13-27$ & $7(2.83)$ \\
$\geq 28$ & $95(38.46)$ \\
$28-32$ & $18(7.28)$ \\
$33-36$ & $33(13.36)$ \\
$37-40$ & $35(14.17)$ \\
$41-43$ & $9(3.64)$ \\
Postpartum & $130(52.63)$ \\
Booked & $72(29.14)$ \\
Unbooked & $175(70.85)$ \\
\hline
\end{tabular}

The most common indication of admission to ICU was hypertensive disorders in pregnancy (45.3\%) followed by obstetric hemorrhage $(39.27 \%)$. Sepsis was the cause in ten $(4.04 \%)$ cases.

\begin{tabular}{|c|c|}
\hline Diseases & Number (\%) \\
\hline $\begin{array}{l}\text { Hypertensive disorders in } \\
\text { pregnancy }\end{array}$ & $112(45.34)$ \\
\hline Severe preeclampsia & $84(34)$ \\
\hline $\begin{array}{l}\text { Chronic hypertension with } \\
\text { superimposed preeclampsia }\end{array}$ & $3(1.21)$ \\
\hline Eclampsia & $22(8.90)$ \\
\hline HELLP syndrome & $3(1.21)$ \\
\hline Obstetric hemorrhage & $97(39.27)$ \\
\hline Ruptured ectopic pregnancy & $8(3.23)$ \\
\hline $\begin{array}{l}\text { Incomplete abortion with severe } \\
\text { anemia }\end{array}$ & $7(2.83)$ \\
\hline $\begin{array}{l}\text { Molar pregnancy with } \\
\text { complications }\end{array}$ & $9(3.64)$ \\
\hline Placenta previa & $12(4.85)$ \\
\hline Abruptio placenta & $6(2.42)$ \\
\hline Ruptured uterus & $18(7.28)$ \\
\hline Retained placenta & $7(2.83)$ \\
\hline Uterine inversion & $1(0.40)$ \\
\hline Placenta increta & $1(0.40)$ \\
\hline Primary PPH & $24(9.71)$ \\
\hline Secondary PPH & $4(1.61)$ \\
\hline Sepsis related & $10(4.04)$ \\
\hline Puerperal sepsis & $2(0.80)$ \\
\hline Septic abortion & $2(0.80)$ \\
\hline Choriooamnionitis & $5(2.02)$ \\
\hline Obstructed labour & $1(0.40)$ \\
\hline Others & $28(11.33)$ \\
\hline Severe anemia & $3(1.21)$ \\
\hline Neurological disorder & $6(2.42)$ \\
\hline Cardiopulmonary arrest & $1(0.40)$ \\
\hline Pulmonary embolism & $1(0.40)$ \\
\hline Lower respiratory tract infection & $2(0.80)$ \\
\hline Pleural effusion & $2(0.80)$ \\
\hline $\begin{array}{l}\text { Gestational Diabetes Mellitus } \\
\text { (GDM) }\end{array}$ & $2(0.80)$ \\
\hline Heart disease & $4(1.61)$ \\
\hline Cardiomyopathy & $2(0.80)$ \\
\hline Epilepsy & $2(0.80)$ \\
\hline Post partum psychosis & $3(1.21)$ \\
\hline
\end{tabular}




\begin{tabular}{|lc|}
\hline Table 3. Interventions required in & MICU $(\mathrm{n}=247)$. \\
\hline Interventions required & Number $(\%)$ \\
Mechanical ventilation & $6(2.42)$ \\
DC shock & $3(1.21)$ \\
Vasoactive infusion & $29(11.74)$ \\
Intensive monitoring & $104(42.10)$ \\
$\mathrm{MgSO}_{4}$ therapy & $53(21.45)$ \\
Antihypertensive therapy & $96(38.86)$ \\
Blood transfusion & $97(39.27)$ \\
FFP transfusion & $29(11.74)$ \\
PRP transfusion & $5(2.02)$ \\
\hline
\end{tabular}

Ten cases $(4.04 \%)$ of postpartum hemorrhage ( $\mathrm{PPH})$ were managed by balloon tamponade, seven $(2.83 \%)$ by B-Lynch compression sutures and three (1.21\%) necessitated cesarean hysterectomy due to intractable hemorrhage. These were due to placenta increta, twins with placenta previa type IIb and placenta previa type IIa.

Among 18 cases of ruptured uterus, 13 (5.26\%) were repaired while five $(2.02 \%)$ required hysterectomy, among which four cases were grand multipara, unbooked and was brought to ER in second stage of labour with hemorrhagic shock, two of them had intrauterine fetal death. Another was a case of misoprostol induction in which the uterus ruptured at $3 \mathrm{~cm}$ dilatation.

The mean stay at MICU was 2.8 days (range: 1-14 days).

\begin{tabular}{|ll|}
\hline Table 4. Stay in ICU $(\mathrm{n}=247)$ & \\
\hline Day(s) & Number (\%) \\
1 & $59(23.88)$ \\
2 & $74(29.95)$ \\
3 & $50(20.24)$ \\
$4-10$ & $60(24.29)$ \\
$11-14$ & $4(1.61)$ \\
\hline
\end{tabular}

Twenty-six $(10.52 \%)$ were referred from various hospitals mostly from periphery. However, 113 (45.74\%) had landed in emergency room (ER) for the first time with severe complications. Ten (4.04\%) were referred to multidisciplinary centers.

During the study period, maternal mortality occurred in four $(1.61 \%)$ of the cases. One was a case of severe preeclampsia who died on 4 th post-opertive day (POD) due to pulmonary embolism. The other case was 40 years grandmultipara, a referred case of molar pregnancy who was brought to ER in moribund condition associated with disseminated intravascular coagulation (DIC) and multiorgan failure and died after 2 hours. Another case, on her $2^{\text {nd }}$ postpartum day (PPD) following home delivery was presented to ER with septic shock and multiorgan failure and died the next day. The fourth case was anesthetic complication. When general anesthesia (GA) was given after subarachnoid block (SAB) failure, patient had bronchospasm and died of cardiopulmonary arrest due to suspected hypersensitivity reaction leading to pulmonary edema.

\section{DISCUSSION}

A total of 247 obstetric cases were admitted to MICU during the study period accounting for $1.28 \%$ of all deliveries. This is similar to the study conducted by Togal et al. ${ }^{8}$ In several other studies, the incidence varied from $0.1-0.9 \%{ }^{9-11}$ In the present study, majority of the patients were young between 20-34 years of age $(79.7 \%)$, while $27(10.9 \%)$ were $\geq 35$ years of age. Most were multipara (50.2\%) and primipara (47.3\%) but grandmultis accounted for $2.42 \%$ of cases. This is similar to studies conducted in Hyderabad and Pakistan. ${ }^{12,13}$ A study conducted in Hyderabad showed majority of patients $63(76 \%)$ were young between 21-30 years of age and mostly 41 (49.4\%) women were multipara, $26(31.3 \%)$ were primipara while 16 $(19.3 \%)$ women were grandmultipara. ${ }^{12}$

Postpartum cases $(52.6 \%)$ were more than the antepartum cases in our study $(47.36 \%)$ which is similar to other studies. ${ }^{7,9,14}$ However, this is in contrast with the previous study conducted in Hyderabad, where antepartum cases were $78 \%$ and postpartum $22 \% .{ }^{12}$ In the present study, most of the patients were $37-40$ weeks of gestation which is similar to other studies. ${ }^{12,15}$ Lack of antenatal care was associated with risk factor for ICU admission as majority $70.8 \%$ of our patients were unbooked, as observed in other studies being $77 \%$ and $84.2 \% .^{12,16}$ In the present study, the most common indication of ICU admission was hypertensive disorder of pregnancy $(45.34 \%)$ followed by obstetric hemorrhage $(39.27 \%)$. This is similar to several other studies which showed that preeclampsia/eclampsia was the predominant indication for admission to their ICUs. ${ }^{17-19}$ Some other 
studies have shown that obstetric hemorrhage was the predominant diagnosis for admission..$^{20-24}$ Most studies were in agreement that preeclampsia/ eclampsia and obstetric hemorrhage were the commonest diagnoses for admission to the ICUs. ${ }^{6,7,19,20,22,25-27}$ In our study, though sepsis was less common (4.04\%), it accounted for $10 \%$ of ICU admission in some studies ${ }^{10,12}$ while $17 \%$ and $26.7 \%$ in others. ${ }^{9,13}$

In the present study, seven cases $(2.8 \%)$ of $\mathrm{PPH}$ was managed with B-Lynch compression sutures while eight cases required hysterectomy, five for ruptured uterus and three for intractable PPH. In other studies, two patients were managed with modified B-Lynch compression sutures ${ }^{12}$ and hysterectomy due to haemorrhage was carried out in seven, two and ten patients. ${ }^{8,12,16}$ The interventions required are depicted in Table 3. This is in accordance with the study by Anwari et $\mathrm{al}^{20}$ where ionotropic support (9\%), $\mathrm{MgSO}_{4}$ therapy $(25 \%)$ were needed and almost one third of patients received antihypertensive therapy, blood and blood products (46\%). In another study, $66 \%$ of the patients required packed erythrocyte transfusions and $33 \%$ of the patients required platelet transfusions, whereas $66 \%$ of the patients required fresh frozen plasma transfusions. ${ }^{8}$ The timely and appropriate management with these therapies would definitely save a mother's life. The mean stay at MICU was 2.8 days (range: 1-14 days) which is comparable with the previous study in which the period of stay in ICU varied from 1-20 days ${ }^{12}$ and 1-15 days. ${ }^{28}$ Prolonged ICU stay reflects the severity of the complication. The percentage of the obstetric patients requiring mechanical ventilation in the ICU has been reported as $19 \%$ by Selo-Ojeme et al, ${ }^{29} 36 \%$ by Anwari et al, ${ }^{20}$ $41 \%$ by Cohen et al, ${ }^{30}$ and $64 \%$ by Tripathi et al, ${ }^{31}$ are all much higher than the present study rates of $(2.42 \%)$.. This could be due to early and elective admission to ICU in high-risk patients in our study.

In the present study, though twenty-six (10.52\%) were referred from periphery hospitals, others have landed to ER for the first time with severe complications (45.74\%). Ten (4.04\%) were referred to multidisciplinary centers. Therefore early recognition of complications and early referral would help in reducing admisiions to ICU setup and therby the morbidity associated with it. The maternal mortality rate from different parts of India, revealed maternal mortality of $41.67 \%$ (Rajasthan) ${ }^{15}$ and $43.63 \%$ (Ludhiana, Punjab) $^{28}$ and was quite high $68.4 \%$ in the study conducted in Karachi ${ }^{16}$ while the rate varied between 1.3 - $41.2 \%$ in different studies. ${ }^{6,7,9,13,17,31,32}$ In the present study, maternal mortality occurred in four $(1.61 \%)$ of the cases. One was a case of severe preeclampsia who died on $4^{\text {th }}$ POD due to pulmonary embolism, another due to anesthetic complication and the other two died of septic shock and multiorgan failure. Similarly, in one study, multiorgan failure has been reported to be the most common cause of maternal death in the obstetric patients. ${ }^{33}$ However, the low maternal mortality in our study is encouraging. Early admission and appropriate management of critical obstetric patients to the ICU may decrease maternal morbidity and mortality. The need for maternal intensive care should be one of the most important measures to be considered in the quality of maternal care.

\section{CONCLUSIONS}

Hypertensive disorders of pregnancy and obstetric hemorrhage appeared as the major risk factors for admission to an intensive care unit thereby influencing maternal outcome in obstetric patients.

\section{DISCLOSURE}

The authors report no conflicts of interest in this work.

No violation of human rights and safety.

Funding: Nil 


\section{REFERENCES}

1. Waterston M, Bewley S, Wolfe C. Incidence and predicators of severe obstetric morbidity: case control study. BMJ. 2001;322:1089-93.

2. Atrash HK, Alexander S, Berg CJ. Maternal mortality in developed countries: not just a concern of the past. Obstet Gynecol. 1995;86:700-5

3. Berg CJ, Atrash HK, Koonin LM, Tucker M. Pregnancyrelated mortality in the United States, 1987-1990. Obstet Gynecol. 1996;88:161-7.

4. Panchal S, Arria AM, Harris AP. Intensive care utilization during hospital admission for delivery: prevalence, risk factors, and outcomes in a statewide population. Anesthesiology. 2000;92:1537-44

5. Collop NA, Sahn SA. Critical illness in pregnancy: an analysis of 20 patients admitted to a medical intensive care unit. Chest. 1993; 103:1548-52.

6. Quah TC, Chiu JW, Tan KH, Yeo SW, Tan HM. Obstetric admissions to the intensive therapy unit of a tertiary care institution. Ann Acad Med Singapore. 2001;30:250-3

7. Okafor UV, Aniebue U. Admission pattern and outcome in critical care obstetric patients. Int J Obstet Anesth. 2004;13:164-6.

8. Togal T, Yucel N, Gedik E, Gulhas N, Toprak IH, Ersoy MO Obstetric admissions to the intensive care unit in a tertiary referral hospital. Journal of Critical Care. 2010;25:628-33.

9. Richa F, Karim N, Yazbeck P. Obstetric admissions to the intensive care unit: An eight- year review. J Med Liban. 2008;56(4):215-9

10. Demirkiran O, Dikmen Y, Utku T, Urkmez S. Critically ill obstetric patients in the intensive care unit. Int $\mathrm{J}$ Obstet Anesth. 2003;12(2):266-70.

11. Hazelgrove JF, Price C, Pappachan VJ, Smith GB. Multicentre study of obstetric admission to 14 intensive care units in southern England. Crit Care Med. 2001;29(4):770-5.

12. Shaikh S, Shaikh NB, Abassi R, Balouch R. Obstetric admission to the intensive care care unit: a one year review. Medical Channel. 2013;19(3):59-63.

13. Bibi S, Memon A, Sheikh JM, Qureshi AH. Severe acute maternal morbidity and intensive care in a public sector university hospital of Pakistan. J Ayub Med Coll Abbotabad. 2008;20(1):109-12.

14. Leung YWN, Lau ACW, Chan KKC, Yan WW. Clinica characteristics and outcomes of obstetric patients admitted to the intensive care unit: a 10-year retrospective review. Hong Kong Med J. 2010;16:18-25

15. Gupta S, Naithani U, Doshi V, Bhargava V, Vijay BS Obstetric critical care; A prospective analysis of clinical characterstics, predictability, and fetomaternal outcome in a new dedicated obstetric intensive care unit. Indian J Anaesth. 2011;55:146-53
16. Baloch R, Jakhrani NK, Zeb E, Hafeez S, Abassi M, Abassi FN. Pattern and outcome of obstetric admissions to the surgical intensive care unit - a ten years study. JSP. 2010;15(4):171-6.

17. Jenkins TM, Troiano NH, Graves CR, Baird SM, Boehm FH. Mechanical Ventilation in an obstetric population; characteristics and delivery rates. Am J Obstet Gynecol. 2003;18:549-52.

18. Platteau P, Engelhardt T, Moodley J, Muckart DJ. Obstetric and gynecological patients in an intensive care unit: a 1-year review. Trop Doct. 1997;27:202-6.

19. Kilpatrick SJ, Matthay MA. Obstetric patients requiring critical care: a five-year review. Chest. 1992;101:1407-12.

20. Anwari JS, Batt AA, AL-Dar MA. Obstetric admissions to the intensive care unit. Saudi Med J. 2004;25:1394-9.

21. Mirghani HM, Hamed M, Ezimokhai M, Weerasinghe DS. Pregnancy related admissions to the intensive care unit. Int J Obstet Anaesth. 2004;13:82-5.

22. Mahuette NG, Murphy-Kaulbeck L, Le Q, Solomon J, Benjamin A, Boyd ME. Obstetric admissions to the intensive care unit. Obstet Gynecol. 1999;94:263-6.

23. Tang LC, Kwok AC, Wong AY, Lee YY, Sun KO, So AP. Critical care in obstetrical patients: an eight year review. Chin Med J (Engl). 1997;110:936-41.

24. Karnad DR, Lapsia V, Krishnan A, Salvi VS. Prognostic factors in obstetric patients admitted to an Indian intensive care unit. Crit Care Med. 2004;32(6):1294-9.

25. Ebirim, L.N., Ojum S. Admissions of obstetric patients in the intensive care unit: a 5 year review. JMMS. 2013;3(11):741-4.

26. Rana A, Baral G, Dangal G. Maternal near-miss: a multicentre surveillance in Kathmandu valley. JNMA. 2013;52(190):299304

27. Saha R, Shakya A. Study of obstetric patients admitted to intensive care unit at Kathmandu Medical College Teaching Hospital. JKMC. 2013;2(4)6:196-200.

28. Yuel VI, Kaur V, Kaur G, Andappan A, Afzal L. Critical care in obstetrics - scenario in a developing country. J Obstet Gynecol India. 2008;58(3):217-20.

29. Selo-Ojeme DO, Omosaiye M, Battacharjee P, Kadir RA. Risk factors for obstetric admissions to the intensive care unit in a tertiary hospital: a case-control study. Arch Gynecol Obstet. 2005;272:207-10

30. Cohen J, Singer P, Kogan A, Hod M, Bar J. Course and outcome of obstetric patients in a general intensive care unit. Acta Obstet Gynecol Scand. 2000;79:846-50.

31. Tripathi R, Rathore AM, Saran S. Intensive care for critically ill obstetric patients. Int J Gynaecol Obstet. 2000;68:257-8.

32. Faponle AF, Adenekan AT. Obstetric admission into the intensive care unit in a sub-urban University Teaching Hospital. NJOG. 2011;6(2):33-6.

33. Karnad DR, Guntupalli KK. Critical illness and pregnancy: review of a global problem. Crit Care Clin. 2004;20:555-76. 